\section{Using a Scanner-based Minirhizotron System to Characterize Sweetpotato Adventitious Root Development during the Initial Storage Root Bulking Stage}

\author{
Arthur Villordon ${ }^{1}$ \\ Louisiana State University Agricultural Center Sweet Potato Research \\ Station, 130 Sweet Potato Road, Chase, LA 71324 \\ Don LaBonte and Julio Solis \\ Louisiana State University Agricultural Center School for Plant, Environmental, \\ and Soil Sciences, Baton Rouge, LA 70803
}

Additional index words. Ipomoea batatas, storage root initiation, anomalous cambium, lateral roots

\begin{abstract}
A scanner-based minirhizotron (MR) system detected initial adventitious root (AR) development associated with transplant establishment. The system also documented the transition of ARs into pencil roots (PRs) and, in some cases, storage roots (SRs). In general, the MR system underestimated destructive sampling-based (DS) estimates of newly initiated AR (NAR), PR, and SR counts. Angled or vertical single sampling tubes underestimated NAR count by $85 \%$ and $79 \%$, respectively. Regardless of installation position, single tube-based measurements underestimated PR and SR count by $83 \%$ and $95 \%$, respectively. However, it was found that two vertically installed tubes underestimated NAR count by only $48 \%$. The potential ability of paired sampling tubes to discriminate NAR count differences in response to experimental treatments was confirmed in a simple rain shelter experiment. The paired MR and DS systems detected $83 \%$ and $56 \%$ reduction in NAR count among plots with rain shelters, respectively. However, it appeared that the presence of tubes interfered with SR formation of monitored AR segments. Despite this limitation, the results show the potential for incorporating MR systems in ongoing and future studies that aim to qualitatively and quantitatively document sweetpotato $A R$ system response to agroclimatic variables and management interventions during the initial SR bulking stage.
\end{abstract}

Root growth and architecture are important factors that influence plant performance and survival yet are frequently overlooked in horticultural research (Wright and Wright, 2004). Root architecture has previously been defined as referring to the spatial configura-

Received for publication 2 Sept. 2010. Accepted for publication 1 Dec. 2010.

Portions of this research were supported by Research Grant No. US-4015-07 from BARD, the U.S.-Israel Binational Agricultural Research and Development, NSF/EPSCoR under Award No. EPS-0701491, USDA NIFA SCRI 2009-51181-06071, and the Louisiana Sweetpotato Advertising and Development Fund.

We are grateful to CID Bio-Science, Inc. for making available the CI-600 root growth monitoring system used in this study. We thank anonymous reviewers for suggestions that substantially improved the clarity of the article.

Approved for publication by the Director of the Louisiana Agricultural Experiment Station as manuscript number 2010-260-9658.

Mention of trademark, proprietary product or method, and vendor does not imply endorsement by the Louisiana State University Agricultural Center nor its approval to the exclusion of other suitable products or vendors.

${ }^{1}$ To whom reprint requests should be addressed; e-mail avillordon@agcenter.1su.edu. potential. Eguchi (2000) described an enclosed system for non-destructively studying SR development using a hydroponic growth medium. The system measured SR diameter with a laser micrometer that was connected to a computer controller. Although this approach enabled time course measurements of SR response to experimental treatments, measurements were limited to pre-selected initiated SRs. Destructive sampling has been routinely used in field (Lowe and Wilson, 1974) and pot experiments (Villordon et al., 2009a, 2009b). In other plant species, non-disruptive methods incorporating rhizotrons and minirhizotrons are routinely used as supplementary or standalone systems to study root growth and architecture. Rhizotrons are typically expensive to construct and operate (Taylor et al., 1990); hence, minirhizotrons have become an alternative method of studying root systems in situ. Minirhizotrons involve installing a clear tube in the soil and lowering an imaging device into the tube to observe roots. A minirhizotron system has been defined by Brown and Upchurch (1987) as a "multicomponent assembly that visually or photographically records normally inaccessible plant roots growing within the soil." The minirhizotrons are typically installed vertically, horizontally, or at angle $30^{\circ}$ to $45^{\circ}$ from the vertical to prevent roots from following the tube for long distances (Taylor et al., 1990). The devices used to document root development have included "periscope"-type devices, endoscopes, boroscopes, fiberoptics, fiberoptics with cameras, illuminated mirrors, and miniature video cameras (Johnson et al., 2001). Recently, a scanner-based method for capturing root data in minirhizotrons has become available. Scanners have previously been used for rhizotron "windows" (Dong et al., 2003; Pan et al., 1998). This scanner-based minirhizotron system has been used in describing drought effects on fine root response of European beech (Facus sylvatica) (Meier and Leuschner, 2008), quantifying root biomass in peashrub (Caragana korshinskii) (Zhang et al., 2009), documenting fine root dynamics of a rainforest transect (Graefe et al., 2008), quantifying fine root response to below-ground carbon fluxes in two cottonwood species (Populus angustifolia and P. fremontii) (Fischer et al., 2007), and calculating the correlation between high tannin leaves and root number in Populus (Fischer et al., 2006).

There are virtually no published data for the use of a rhizotron, minirhizotron, or similar systems in quantifying sweetpotato AR development response to experimental treatments during the initial SR bulking stage. The overall objective of this study was to determine the usefulness of a scanner-based minirhizotron system in monitoring $\mathrm{AR}$ development and architecture during the initial SR bulking stage under uniform management conditions for experimental fields in Chase, LA. The first phase of this work involved determining the appropriate position and number of sampling or access tubes for the experimental conditions used in the study. The second phase investigated the discriminating capability of minirhizotrons in 
measuring AR response to soil moisture variability in a simple rain shelter experiment.

\section{Materials and Methods}

Growing conditions and treatments. All field experiments were carried out from 27 Aug. 2009 to 2 Oct. 2009 and 8 June 2010 to 14 July 2010 in well-drained research fields in Chase, LA (long. $32^{\circ} 6^{\prime} \mathrm{N}$, lat. $91^{\circ} 42^{\prime} \mathrm{W}$ ). The soil taxonomic class of the experimental site was fine-silty, mixed, active, thermic Typic Glossaqualfs. The bulk density at the $7-\mathrm{cm}$ and $30-\mathrm{cm}$ depths was $1.1 \mathrm{~g} \cdot \mathrm{cm}^{-3}$ and $1.5 \mathrm{~g} \cdot \mathrm{cm}^{-3}$, respectively. For this location, SRs are not typically found below $30 \mathrm{~cm}$. Research plots were prepared by disk cultivating fields followed by broadcast application of chlorpyrifos insecticide $(2.2 \mathrm{~kg}$ a.i./ ha). A second disking operation was performed and then rows were formed on 1-m centers. Plots were fertilized with $25 \mathrm{~kg} \cdot \mathrm{ha}^{-1}$ nitrogen, $118 \mathrm{~kg} \cdot \mathrm{ha}^{-1} \mathrm{P}_{2} \mathrm{O}_{5}$, and $135 \mathrm{~kg} \cdot \mathrm{ha}^{-1}$ $\mathrm{K}_{2} \mathrm{O}$. Herbicide application, consisting of a tank mix of clomazone (840 g.ha $\left.\mathrm{ha}^{-1}\right)$ and flumioxazin $\left(36 \mathrm{~g} \cdot \mathrm{ha}^{-1}\right)$, was performed immediately before planting. To reduce variability associated with planting operations, especially in transplant selection and depth of setting, only one person performed selection and setting of transplants in both years. Transplants were obtained from virus-tested 'Beauregard' G1 seed beds and were manually set within $1 \mathrm{~d}$ of cutting. In 2009, plots were $3 \mathrm{~m}$ long (in-row spacing between plants $=30 \mathrm{~cm}$ ); in 2010 , plots were $1.5 \mathrm{~m}$ long (in-row spacing between plants $=30 \mathrm{~cm})$. In both years, additional plots (minimum of four replications) were established for destructive sampling to verify transplant establishment (3 to 7 DAT) and initial SR bulking (28 to 35 DAT). We have previously defined transplant establishment as the detection of at least one AR in at least $50 \%$ of transplants from a sample (Villordon et al., 2009b). We have also defined initiated SRs at 28 to 35 DAT as any pigmented AR with localized swelling $0.5 \mathrm{~cm}$ or greater at the widest point (Villordon et al., 2009b). The timing of sampling for the specific stages has previously been calibrated for this location based on soil moisture regimes and growing degree-days (Villordon et al., 2009b). In 2009, each transplant was watered with $\approx 177 \mathrm{~mL}$ water. In 2010 , some plots were subjected to portable rain shelter treatments and were not watered in at planting. The treatments in the 2010 experiment were arranged in a randomized block design. For each monitored plot, the fifth and third hills were selected for MR monitoring in 2009 and 2010, respectively. Soil moisture monitoring at two depths $(5$ and $15 \mathrm{~cm}$ ) was performed by vertically installed soil moisture sensors (Model 5TE; Decagon Devices Inc., Pullman, WA) linked to automated data loggers (EM50; Decagon Devices Inc.). In situ soil moisture measurements were augmented by a portable device, HydroSense Soil Water Content Management System (CS-620, 20-cm probe, inserted vertically; Campbell Scientific, Inc., Logan, UT). All soil moisture measurement methods were calibrated gravimetrically. In both years, if a rainfall event did not occur within $1 \mathrm{~d}$ of planting, overhead irrigation was applied using a traveling irrigation sprinkler. Subsequently, supplemental irrigation was applied when soil moisture approached $8 \%$ to $10 \%$ volumetric water content (VWC) at the $15-\mathrm{cm}$ depth. In 2010, portable rain shelters were installed in designated plots during irrigation or a rainfall event. For the soil series used in the studies, it was previously determined that field capacity was at $32 \%$ VWC $( \pm 3 \%)$. In 2009, two to three nodes were covered; in 2010, further transplant selection and setting were performed to enable covering of only two nodes. Clear sampling tubes $(36 \mathrm{~cm}$ length; $6.2 \mathrm{~cm}$ internal diameter) were installed with the aid of a post hole digger. The tubes were installed first and then transplants were set $\approx 2.5 \mathrm{~cm}$ from the base of the MRs. In addition to the removable plastic cap, thick cardboard was taped around the protruding sides of the tubes to prevent light transmittance. In 2009, tube positions included vertical (one or two tubes) and angled (one tube positioned $\approx 45^{\circ}$ from the vertical). For the paired vertical tube placement, the MRs were placed on opposite sides of the transplant along the row. For angled tubes, transplants were set to align with the length the tube. Each MR sampling method was replicated seven times (one monitored transplant in each replicate plot). In 2010, two tubes were installed vertically per monitored transplant using the procedure described previously for paired tubes. There were five replications (one monitored plant in each replicate plot) for plots that received the rain shelter treatment and four replications for control plots (no rain shelter). Plots were manually harvested in both years. To reduce damage to roots during destructive sampling, a shovel was inserted vertically $\approx 15$ to $20 \mathrm{~cm}$ from the base of a hill, pushed at an angle $\left(\approx 45^{\circ}\right)$, gently rocked up and down, and carefully lifted and pulled back to recover the soil mass around the AR system.

Measurements. We based our AR classification scheme on previous work by Lowe and Wilson (1974) and Togari (1950). At harvest (36 DAT), ARs were classified as NARs, PRs, and SRs. Togari (1950) described NARs as "young" and non-pigmented. PRs were pigmented ARs that were uniformly thickened and were not capable of becoming SRs (Togari, 1950; Wilson and Lowe, 1973). SRs were pigmented ARs with localized swelling (0.5 $\mathrm{cm}$ or greater). We followed the characterization of pigmentation (cream, pink, or red) as described by Lowe and Wilson (1974). The main difference between PR and SR was the presence of secondary or anomalous cambium activity (Togari, 1950; Wilson and Lowe, 1973) resulting in localized swelling and subsequent SR expansion in the latter. Only root segments (non-pigmented) with visible firstorder lateral root growth were scored as NARs.

Minirhizotron-based measurements were made with the CI-600 root growth monitoring system (CID Bio-Science, Camas, WA). In 2009, daily scans were made until trans- plant establishment (detection of AR). AR presence was confirmed through sequential destructive sampling (minimum of five plants per day; 3 to 7 DAT). Subsequently, scans were made every $7 \mathrm{~d}$ thereafter until detection of initial SR bulking as confirmed by destructive sampling (minimum of five plants per day; 28 to 35 DAT). In 2010, daily scans were made after planting until detection of presumptive AR (confirmed through destructive sampling of a minimum of five plants per day, 28 to 35 DAT). Thereafter, daily scans were made to track AR development of monitored segments until no observable changes were detected, e.g., changes in length or lateral growth events (up to 15 DAT). Subsequently, daily scans were made every 3 to $5 \mathrm{~d}$ until first detection of SR bulking as confirmed by destructive sampling. All images were scanned using the default software settings that included turning off the auto brightness and contrast. These settings helped in standardizing the color intensity of images (Dong et al., 2003). All images were scanned at $\approx 78 \mathrm{dots} / \mathrm{cm}$. Scanned images were manually interpreted based on the AR classification scheme defined previously. In 2009, destructive sampling-based AR counts were combined for all nodes and the cut end of the transplant. In 2010, destructive sampling-based AR counts were collected for each node (proximal and distal node relative to the soil surface) and the cut end. Statistical analyses were performed on square root-transformed root count values with significant differences inferred at $P<0.05$. All statistical analyses were performed using SAS (Version 9.2; SAS Institute, Cary, NC).

\section{Results and Discussion}

Adventitious root growth dynamics after planting. In both years, destructive sampling showed that ARs at least $1 \mathrm{~cm}$ long were present in at least $50 \%$ of all transplants at 5 DAT (data not shown). We have previously called the transplant establishment stage SR1 (Villordon et al., 2009b). This presumptive phenological stage corresponds to Togari's (1950) "sub-stage VII" in the early "tuberous root thickening stage," characterized by completion of the primary cambium layer. However, it was not until after 7 DAT that ARs were first detected in at least $50 \%$ of transplants subjected to scanner-based MR analysis (Fig. 1A). Once ARs were initiated, growth of monitored root segments occurred at a relatively rapid rate within the first 10 DAT. For example, the length of a monitored AR segment doubled within a period of $24 \mathrm{~h}$ (7 to 8 DAT) (Fig. 1B), and first-order lateral root development was distinct at $9 \mathrm{DAT}$ for this monitored segment (Fig. 1C). These observations were consistent in four of 12 monitored AR segments (data not shown). This monitored segment eventually became a PR at 36 DAT (Fig. 1D). Although we did not routinely detect SR formation using MR, we were able to document progression of SR formation in a monitored AR segment between 22 DAT (Fig. 1E) and 36 DAT (Fig. 1F). Figure 1E also shows overlapping first-order 
lateral roots (marked with " $\mathrm{x}$ ") in the monitored area. This capability to monitor AR growth and development in situ demonstrates the capability of MRs to generate qualitative evidence that is not possible using conventional destructive sampling methods. This also represents "one of the greatest strength of minirhizotrons, i.e., the ability to monitor specific root segments at frequent time intervals" (Johnson et al., 2001). The MR-based documentation of AR growth dynamics corroborated Togari's (1950) destructive sampling-based observations, i.e., AR length more than doubled every $5 \mathrm{~d}$ during the 5 - to 15 DAT period for the given experimental conditions. Previous studies on AR development and SR initiation (Lowe and Wilson, 1974; Togari, 1950; Villordon et al., 2009a, 2009b; Wilson and Lowe, 1973) did not address the role of lateral roots in SR development. However, Clark and Matthews (1987) documented the role of lateral roots as entry points for soil rot disease caused by Streptomyces ipomoea. This disease typically results in abnormal SR shape and growth. Thus, current available evidence suggests that a healthy lateral root system is necessary for normal SR development, assuming all other growth-related variables are not limiting. The detection of lateral root development at 9 DAT by the MR system further suggests the potential of such system to enhance the understanding of variables that negatively affect AR development during the early phase of the SR bulking stage. To our knowledge, these observations represent the first MR-based documentation of in situ sweetpotato AR growth dynamics.

Relationship among destructive sampling and minirhizotron-based adventitious root counts. In general, MR-based estimates of NARs, PRs, and SRs underestimated actual counts as determined by destructive sampling (Table 1). Single vertically installed tubes underestimated NAR, PR, and SR count by $79 \%, 83 \%$, and $95 \%$, respectively. Angled vertical tubes underestimated NAR, PR, and SR count by $85 \%, 83 \%$, and $95 \%$, respectively. These observations were consistent with past observations that MR-based root studies generally sampled a relatively small portion of the total root system (Bragg et al., 1983; Yao et al., 2009). However, it was found that two vertically installed tubes underestimated NAR count by only $48 \%$. Although past reports have indicated that increasing the number of MRs can reduce the sampling variance (Rygiewicz et al., 1997), this number has to be optimized for tube placement angle and the species under consideration (Johnson et al., 2001). For example, it has been documented in spring oat (Avena sativa) that angled MRs decreased the sampling variance because roots that contacted the angled tubes were observed to grow around and then away from the lower face, whereas roots were channeled down the tubesoil interface of vertically installed MRs (Bragg et al., 1983). However, because ARs were initiated along multiple nodes of the main axis of the sweetpotato transplant, the paired vertical placement appeared more optimal given the experimental conditions. In
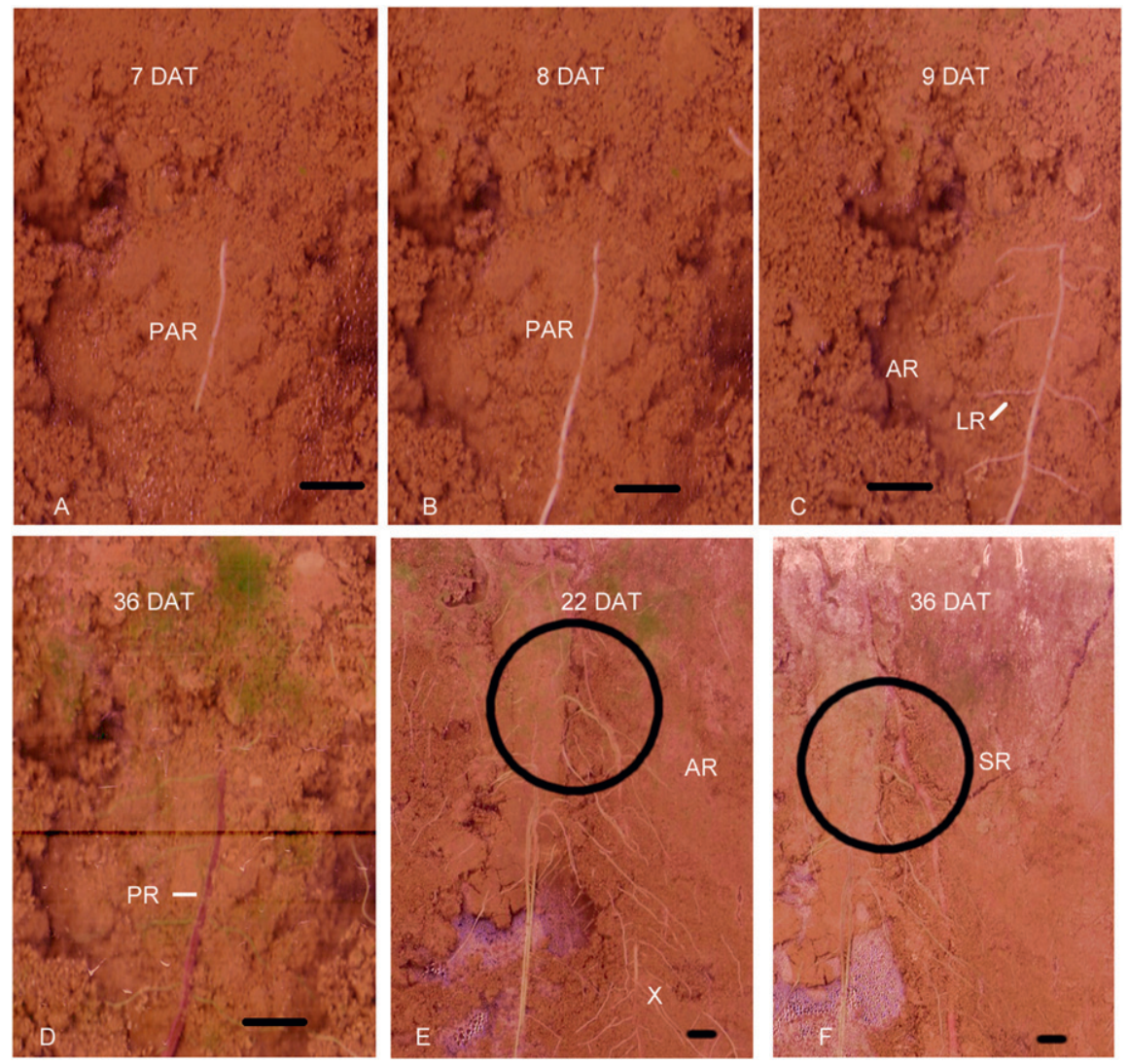

Fig. 1. Developing adventitious root (A-C), pencil root (D), and progression of storage root development (E-F; encircled) documented using a scanner-based minirhizotron system in sweetpotatoes grown in Chase, LA. Each of the A-D and $\mathbf{E}-\mathbf{F}$ series of scans (vertical tube) was made on a single plant grown in each of the 2010 and 2009 growing seasons, respectively. Scale bar $=1 \mathrm{~cm}$. DAT $=$ days after planting; $\mathrm{PAR}=$ presumptive adventitious root; $\mathrm{AR}=$ adventitious root; $\mathrm{LR}=$ lateral root; $\mathrm{PR}=$ pencil root; $\mathrm{SR}=$ storage root; $\mathrm{x}=$ overlapping lateral roots. Details of the experimental approach and other procedures are defined in "Materials and Methods."

Table 1. Counts of newly initiated adventitious roots, pencil roots, and storage roots during the initial storage root bulking stage as determined using destructive sampling and scanner-based minirhizotron system in sweetpotatoes grown in Chase, LA. ${ }^{\mathrm{z}}$

\begin{tabular}{lccc}
\hline & \multicolumn{3}{c}{ Adventitious root state $^{\mathrm{x}}$} \\
\cline { 2 - 4 } Sampling method $^{\mathrm{y}}$ & NAR & PR & SR \\
\hline Destructive sampling & $4.9 \pm 0.6 \mathrm{a}$ & $4.3 \pm 0.5 \mathrm{a}$ & $2.2 \pm 0.3 \mathrm{a}$ \\
MR-angled & $0.7 \pm 0.4 \mathrm{c}$ & $0.7 \pm 0.3 \mathrm{c}$ & $0.1 \pm 0.1 \mathrm{~b}$ \\
MR-vertical (1) & $1.0 \pm 0.3 \mathrm{c}$ & $0.7 \pm 0.5 \mathrm{c}$ & $0.1 \pm 0.1 \mathrm{~b}$ \\
MR-vertical (2) & $2.5 \pm 0.6 \mathrm{~b}$ & $1.7 \pm 0.5 \mathrm{c}$ & $0 \mathrm{~b}$ \\
\hline
\end{tabular}

${ }^{\mathrm{z} V a l u e s}$ represent means $( \pm$ SEM). Means within columns followed by different letters are significantly different based on Fisher's least significant difference mean separation test $(P<0.05)$. Analysis was performed on square-transformed values. Date planted: 27 Aug. 2009. Date harvested: 2 Oct. 2009. Corresponding non-transformed values are shown. Classification of adventitious roots was performed at harvest. Details of the experimental approach and other procedures are defined in "Materials and Methods."

${ }^{y}$ Destructive sampling values represent mean of four replicates. MR $=$ minirhizotron-based sampling. Number of replicates for MR sampling $=7$; number of sampled plants per replicate plot $=1$.

${ }^{\mathrm{x}} \mathrm{NAR}=$ newly initiated adventitious root, non-pigmented (white or pale white); PR = pencil root, pigmented (orange, pink, or reddish) adventitious roots with no visible localized swelling; SR = storage root, pigmented adventitious roots with visible localized swelling. Vertical $(x)=$ tubes inserted vertically, where $\mathrm{x}=$ number of tubes.

particular, the tube length that we used likely limited the data collection potential of angled tubes. Despite the potential of an MR system to characterize and monitor sweetpotato AR development in situ, there are limitations on relying solely on this method. For example, it appeared that the presence of sampling tubes interfered with SR initiation. This was in part likely the result of the interference with the spatial configuration of AR architecture. For example, the overlapping lateral roots in Figure 1E would likely have assumed a different spatial configuration if the tube was absent. Green et al. (2005) used the concept of "interlateral root competition" in describing the reduction of soil volume exploited by developing Mediterranean shrub (Pistacia lentiscus) roots with shortened internode lengths. 
Table 2. Counts of newly initiated adventitious roots, pencil roots, and storage roots during the initial storage root bulking stage determined using destructive sampling and scanner-based minirhizotron system in sweetpotatoes grown with or without rain-out shelters in Chase, LA. ${ }^{\mathrm{z}}$

\begin{tabular}{|c|c|c|c|c|c|c|}
\hline \multirow{2}{*}{$\begin{array}{l}\text { Sampling } \\
\text { method }^{y}\end{array}$} & \multicolumn{6}{|c|}{ Adventitious root count ${ }^{\mathrm{x}}$} \\
\hline & \multicolumn{3}{|c|}{ Sheltered } & \multicolumn{3}{|c|}{ Non sheltered } \\
\hline$\overline{\mathrm{DS}-\mathrm{N} 1}$ & $0.5 \pm 0.4 \mathrm{a}(\mathrm{b})$ & $0.3 \pm 0.3 \mathrm{a}(\mathrm{c})$ & $0 \mathrm{a}(\mathrm{c})$ & $1.8 \pm 0.3 \mathrm{~b}(\mathrm{bc})$ & $1.4 \pm 0.4 \mathrm{~b}(\mathrm{c})$ & $0.2 \pm 0.1 \mathrm{a}(\mathrm{b})$ \\
\hline DS-CE & $2.0 \pm 0.5 \mathrm{a}(\mathrm{a})$ & $5.2 \pm 0.7 \mathrm{a}(\mathrm{a})$ & $1.5 \pm 0.5 \mathrm{a}(\mathrm{b})$ & $2.7 \pm 0.5 \mathrm{a}(\mathrm{b})$ & $5.4 \pm 0.8 \mathrm{a}(\mathrm{b})$ & $0.9 \pm 0.4 \mathrm{a}(\mathrm{b})$ \\
\hline DS-Total & $2.9 \pm 0.7 \mathrm{a}(\mathrm{a})$ & $6.5 \pm 0.7 \mathrm{a}(\mathrm{a})$ & $2.8 \pm 0.5 \mathrm{a}(\mathrm{a})$ & $6.7 \pm 0.5 \mathrm{~b}(\mathrm{a})$ & $8.8 \pm 1.2 \mathrm{a}(\mathrm{a})$ & $2.1 \pm 0.3 \mathrm{a}(\mathrm{a})$ \\
\hline MR & $0.2 \pm 0.2 \mathrm{a}(\mathrm{b})$ & $2.3 \pm 0.8 \mathrm{a}(\mathrm{b})$ & $0.2+0.2 \mathrm{a}(\mathrm{c})$ & $1.2 \pm 0.4 \mathrm{~b}(\mathrm{c})$ & $2.4 \pm 0.8 \mathrm{a}(\mathrm{c})$ & $0.4 \pm 0.4 \mathrm{a}(\mathrm{b})$ \\
\hline
\end{tabular}

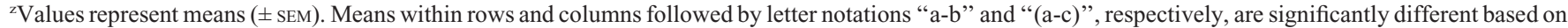
Fisher's least significant difference mean separation test $(P<0.05)$. Analysis was performed on square-transformed values. Corresponding non-transformed values are shown. Classification of adventitious roots was performed at harvest. Description of experimental procedures are found in "Materials and Methods." Date planted: 8 June 2010. Date harvested: 14 July 2010.

${ }^{y} \mathrm{DS}=$ destructive sampling. DS represents mean of four replicates. $\mathrm{N}=$ node location, 1 (proximal) or 2 (distal), relative to soil surface. $\mathrm{CE}=\mathrm{cut}$ end. Total $=$ total count $(\mathrm{N} 1+\mathrm{N} 2+\mathrm{CE})$. MR = minirhizotron-based sampling. Number of replicates for MR sampling = 5; number of sampled plants per replicate plot $=1$.

${ }^{\mathrm{x}} \mathrm{NAR}=$ newly initiated adventitious root, non-pigmented (white or pale white); $\mathrm{PR}=$ pencil root, pigmented (orange, pink, or reddish) adventitious roots with no visible localized swelling; $\mathrm{SR}=$ storage root, pigmented adventitious roots with visible localized swelling.

Despite this limitation, preliminary quantitative data from the current work demonstrate the potential usefulness of incorporating MRbased measurements in ongoing or future sweetpotato research, especially in studies that could lead to enhanced understanding of the possible mitigating role of AR system architecture on the relationship between planting density and potential sweetpotato yield. In addition, there is the potential to document the possible interactive effects of planting density and soil moisture regimes. To our knowledge, such information is not currently available for this globally important crop species.

Minirhizotron-based measurement of adventitious root development response to rain shelter treatments. Both destructive sampling and MR methods detected differences in NAR counts between plots subjected to rain shelter treatments (Table 2). Destructive sampling revealed $56 \%, 26 \%$, and $33 \%$ differences in total NAR, PR, and SR counts, respectively. This method also detected NAR count differences among the individual nodes, i.e., proximal and distal nodes. The MR-based system detected an $83 \%$ difference in NAR count between experimental treatments. In general, the MRbased system underestimated NAR, PR, and SR counts relative to the destructive samplingbased total counts. Previous work on quantifying sweetpotato transplant response using destructive sampling-based AR counts included such experimental treatments as virus presence (Kano and Nagata, 1999), cultivar effects (Wilson and Lowe, 1973), and multiple variables, including soil moisture and fertilizer rates (Togari, 1950). As a result of the limitations of the current study that included variable internode lengths and fixed scanning depth, we were unable to use MR-based measurements to discriminate differences in NAR, PR, and SR count based on node location. Our work suggests that the number of nodes need to be standardized to improve the analytical capability of MR-based studies in sweetpotatoes. Despite these limitations, our preliminary results demonstrate the potential use of this system in providing unique information regarding the relationship between experimental treatments and AR development during the initial SR bulking period, especially as it relates to irrigation studies. In this case, the MR-based system was able to document differential NAR count in response to rain shelter treatments. During the study, the soil moisture at the $5-\mathrm{cm}$ depth was consistently below $10 \%$ volumetric water content in plots with rain shelters, whereas soil temperatures were consistently above $30{ }^{\circ} \mathrm{C}$ (data not shown). We have previously shown that under these conditions, SRs were generally set at the lower nodes (Villordon et al., 2010). Togari (1950) provided evidence that AR number was related to final SR yield under certain experimental conditions. Thus, the reliable use of an MR system for studying sweetpotato AR development responses will in part depend on preliminary calibration studies for the experimental site and management regime. Such calibration studies may include evaluating the use of multiple tube orientations (vertical and angled), using longer tubes (where applicable), and obtaining scans at various depths. In addition, it is also necessary to test and calibrate the applicability of computer software to routinely perform digital image analysis of scanned sweetpotato AR images. Digital image analysis permits some automation of scanned data and reduces the resources required for manual image analysis, especially if there are is a large number of images to be analyzed. Best practices for the installation and stabilization of MRs have been described elsewhere (Johnson et al., 2001).

\section{Conclusion}

A MR system demonstrated the potential for in situ monitoring of qualitative aspects of early AR growth dynamics and for further understanding the role of AR architecture in the early storage root bulking stage. There is also the potential to use this system to quantitatively discriminate among experimental outcomes in field-based studies, e.g., the influence of various soil moisture regimes on AR development. Such studies are possible assuming that calibration work has been done for location-specific field and management variables. This calibration work is important in determining the degree of variance between a MR system and destructive sampling. Knowledge of this variance is an important prerequisite in determining the applicability of a MR system as a standalone method or as a supplement to destructive sampling. In our studies, the MR system significantly underestimated all AR-related states that were measured. Furthermore, the presence of sampling tubes appeared to reduce $\mathrm{SR}$ formation of monitored $\mathrm{AR}$ segments. These represent important considerations for the use of MR systems in quantifying the effects of experimental treatments on sweetpotato AR development during the initial storage root bulking stage.

\section{Literature Cited}

Bragg, P.L., G. Govi, and R.Q. Canell. 1983. A comparison of methods, including angled and vertical minirhizotrons, for studying root growth and distribution in a spring oat crop. Plant Soil 73:435-440.

Brown, D.A. and D.R. Upchurch. 1987. Minirhizotrons: A summary of methods and instruments in current use, p. 15-30. In: Taylor, H.M. (ed.). Minirhizotron observation tubes: Methods and applications for measuring rhizosphere dynamics. ASA Special Publication Number 50. American Society of Agronomy, Madison, WI

Clark, C.A. and S. Matthews. 1987. Histopathology of sweet potato root infection by Streptomyces ipomoea. Phytopathology 77:1418-1423.

Dong, S., D. Neilsen, G.H. Neilsen, and M. Weis. 2003. A scanner-based root image acquisition technique for measuring roots in a rhizotron window. HortScience 38:1385-1388

Eguchi, T. 2000. Sweetpotato studies for understanding tuberous root growth hidden below ground. Biotronics 29:97-107.

Fischer, D.G., S.C. Hart, C.J. LeRoy, and T.G. Whitham. 2007. Variation in below-ground carbon fluxes along a Populus hybridization gradient. New Phytol. 176:415-425.

Fischer, D.G., S.C. Hart, B.J. Rehill, R.L. Lindroth, P. Keim, and T.G. Whitham. 2006. Do hightannin leaves require more roots? Oecologia 149:668-675.

Graefe, S., D. Hertel, and C. Leuschner. 2008. Fine root dynamics along a 2,000-m elevation transect in South Ecuadorian mountain rainforests. Plant Soil 313:155-166.

Green, J.J., J.A. Baddeley, J. Cortina, and C.A. Watson. 2005. Root development in the Mediterranean shrub Pistacia lentiscus as affected 
by nursery treatments. J. Arid Environ. 61: 1-12.

Johnson, M.G., D.T. Tingey, D.L. Phillips, and M.J. Storm. 2001. Advancing fine root research with minirhizotrons. Environ. Exp. Bot. 45:263289.

Kano, Y. and R. Nagata. 1999. Comparison of the rooting ability of virus infected and virus-free cuttings of sweet potatoes (Ipomoea batatas Poir.) and an anatomical comparison of the roots. J. Hort. Sci. Biotechnol. 74:785-790.

Lowe, S.B. and L.A. Wilson. 1974. Comparative analysis of tuber development in six sweet potato [Ipomoea batatas (L.) Lam] cultivars 1 . Tuber initiation, tuber growth and partition of assimilate. Ann. Bot. (Lond.) 38:307-317.

Lynch, J. 1995. Root architecture and plant productivity. Plant Physiol. 109:7-13.

Meier, I.C. and C. Leuschner. 2008. Genotypic variation and phenotypic plasticity in the drought response of fine roots of European beech. Tree Physiol. 28:297-309.

Pan, W.L., R.P. Bolton, E.J. Lundquist, and L.K. Hiller. 1998. Portable rhizotron and color scanner system for monitoring root development. Plant Soil 200:107-112.

Rygiewicz, P.T., M.G. Johnson, L.M. Ganio, D.T. Tingey, and M.J. Storm. 1997. Lifetime and temporal occurrence of ectomycorrhizae on ponderosa pine (Pinus ponderosa Laws.) seedlings grown under varied atmospheric $\mathrm{CO} 2$ and nitrogen levels. Plant Soil 180:275-287.

Taylor, H.M., D.R. Upchurch, and B.L. McMichael. 1990. Applications and limitations of rhizotrons and minirhizotrons for root studies. Plant Soil 129:29-35.

Togari, Y. 1950. A study of tuberous root formation in sweet potato. Bul. Nat. Agr. Expt. Sta. Tokyo 68:1-96.

Villordon, A., D.R. LaBonte, N. Firon, Y. Kfir, E. Pressman, and A. Schwartz. 2009a. Characterization of adventitious root development in sweetpotato. HortScience 44:651-655.

Villordon, A., D.R. LaBonte, and N. Firon. 2009b. Development of a simple thermal time method for describing the onset of morpho-anatomical features related to sweetpotato storage root formation. Sci. Hort. 21:374-377.
Villordon, A., J. Solis, D. LaBonte, and C. Clark. 2010. Development of a prototype Bayesian network model representing the relationship between fresh market yield and some agroclimatic variables known to influence storage root initiation in sweetpotato. HortScience 45: 1167-1177.

Wilson, L.A. and S.B. Lowe. 1973. The anatomy of the root system in West Indian sweet potato [Ipomoea batatas (L.) Lam] cultivars. Ann. Bot. (Lond.) 37:633-643.

Wright, A.N. and R.D. Wright. 2004. The Horhizotron $^{\mathrm{TM}}$ : A new instrument for measuring root growth. HortTechnology 14:560-563.

Yao, S., I.A. Merwin, and M.G. Brown. 2009. Apple root growth, turnover, and distribution under different orchard groundcover management systems. HortScience 44:168-175.

Zhang, Z.S., X.R. Li, L.C. Liu, R.L. Jia, J.G. Zhang, and T. Wang. 2009. Distribution, biomass, and dynamics of roots in a revegetated stand of Caragana korshinskii in the Tengger Desert, northwestern China. J. Plant Res. 122: 109-119. 